\title{
Correction to: Neuraxial anesthesia and bladder dysfunction in the perioperative period: a systematic review
}

\author{
Stephen Choi, MD $\cdot$ Padraig Mahon, MD $\cdot$ Imad T. Awad, MBChB
}

Published online: 18 December 2017

(C) Canadian Anesthesiologists' Society 2017

\section{Correction to: Can J Anesth/J Can Anesth (2012) 59:681-703 \\ https://doi.org/10.1007/s12630-012-9717-5}

The following row on page 691 of Table 3, as highlighted in bold under Incidence of Retention (\%) should read " 0 " instead of "N/A".

Table 3 Intrathecal anesthesia studies

\begin{tabular}{|c|c|c|c|c|c|c|c|c|c|c|}
\hline $\begin{array}{l}\text { Author/ } \\
\text { Year }\end{array}$ & $\begin{array}{l}\text { Study } \\
\text { Design }\end{array}$ & $\begin{array}{l}\text { Jadad } \\
\text { Score }\end{array}$ & $\mathrm{N}$ & Surgical Class & $\begin{array}{l}\text { Intrathecal } \\
\text { Drug/Dose }\end{array}$ & $\begin{array}{l}\text { Incidence of } \\
\text { Retention }(\%)\end{array}$ & $\begin{array}{l}\text { PVR } \\
(\mathrm{mL})\end{array}$ & $\begin{array}{l}\text { Catheterization } \\
(\%)\end{array}$ & $\begin{array}{l}\text { Infection } \\
(\%)\end{array}$ & Comments \\
\hline $\begin{array}{c}\text { Linares-Gil } \\
2009^{42}\end{array}$ & OBS & N/A & 406 & $\begin{array}{l}\text { GEN }(n=219) \\
\text { ORTHO }(n=187)\end{array}$ & $\begin{array}{l}\text { 3\% Hyperbaric } \\
\text { Lidocaine } \\
0.9 \mathrm{mg} \cdot \mathrm{kg}^{-1}\end{array}$ & 0 & N/A & $0 / 406(0)$ & N/A & $\begin{array}{l}\text { Criteria for } \\
\text { catherization } \\
\text { not indicated }\end{array}$ \\
\hline
\end{tabular}

The original article can be found online at https://doi.org/10.1007/ s12630-012-9717-5.

\section{S. Choi, MD - I. T. Awad, MBChB ( $₫)$}

Department of Anesthesia, Sunnybrook Health Sciences

Centre, University of Toronto, 2075 Bayview Avenue,

Toronto M4N 3M5, Canada

e-mail: imad.awad@sunnybrook.ca

P. Mahon, MD

Department of Anaesthesia and Intensive Care Medicine, Cork

University Hospital, University College Cork, Cork, Ireland 